\title{
Report of a case with T1a gallbladder poorly differentiated adenocarcinoma, solid type, which developed into lymph node metastases
}

\author{
Atsushi Takano ${ }^{1,5^{*}}$, Shota Harai ${ }^{3}$, Hiroshi Nakagomi ${ }^{1}$, Masahiro Maruyama ${ }^{1}$, Atsushi Yamamoto ${ }^{1}$, Hideki Watanabe ${ }^{1}$ \\ Haruka Nakada', Kazushige Furuya', Masao Hada', Yoshiaki Miyasaka', Toshio Oyama² and Masao Omata,
}

\begin{abstract}
We experienced a case with gallbladder carcinoma growing limited to the mucosa (T1a), which developed massive lymphatic vessel spread and lymph node metastases.

A 72-year-old man was referred to our hospital for the swelling of his gallbladder during a routine ultrasound sonography checkup. We diagnosed the patient with gallbladder carcinoma with lymph node metastasis according to the radiographic findings and performed the open cholecystectomy and lymph node dissection. A histological examination showed poorly differentiated adenocarcinoma, solid type, and the tumor was limited to the mucosa. The number of lymphatic vessels was increased in the tumor and peritumor areas, and cancer cells were observed in the lymphatic vessels, which were detected via D2-40 immunohistochemistry. A careful histological examination and follow-up is required for T1a gallbladder carcinoma.
\end{abstract}

Keywords: T1a gallbladder carcinoma, Lymph node metastases, Lymphatic vessels

\section{Background}

The prognosis of gallbladder carcinoma is poor. The 5 -year survival rate of surgical resection was reported to be $40 \%$ [1]. However, patients with T1a gallbladder carcinoma (GC) are considered to be curable by cholecystectomy without lymph node dissection $[2,3]$, and no evidence has shown that the lymph node dissection improves the prognosis of T1a GC [4-6]. Furthermore, the frequency of lymph node metastases of T1a GC was reported to be $0-2.5 \%[6,7]$.

However, we experienced a case with gallbladder carcinoma growing limited in the mucosa developed massive lymphatic vessel spread and lymph node metastases.

We herein report the rare case of lymph node metastases in a patient with GC and discuss the considerations for the etiology of lymph node metastases in this case.

\footnotetext{
* Correspondence: a-takano0902@ych.pref.yamanashi.jp

${ }^{1}$ Department of Surgery, Yamanashi, Japan

${ }^{5}$ 1-1-1 Fujimi Kofu, Yamanashi 400-8506, Japan

Full list of author information is available at the end of the article
}

\section{Case presentation}

A 72-year-old man was referred to our hospital for the swelling of his gallbladder which was indicated during a routine ultrasound sonography checkup. He had been previously treated for hypertension, diabetes mellitus, and a cerebral infarction. He had no family history of cancer. There were no physical abnormalities on this admission. The laboratory data indicated a slight elevation of $\gamma$-GTP at $119 \mathrm{IU} / \mathrm{l}$, but no other abnormal findings. The values of tumor markers were within the normal ranges; CEA, $2.6 \mathrm{ng} / \mathrm{ml}$ and CA199, $29.3 \mathrm{U} / \mathrm{ml}$.

Ultrasound sonography showed an enlarged gallbladder filled with concentrated bile juice and an enlarged lymph node along the GB wall. The wall thickness was not detected (Fig. 1). Computed tomography indicated a contrast-enhanced wall thickness of the neck of gall bladder and swelling of the lymph node measuring $1.2 \mathrm{~cm}$ in diameter (Fig. 2).

\section{勿 Springer}




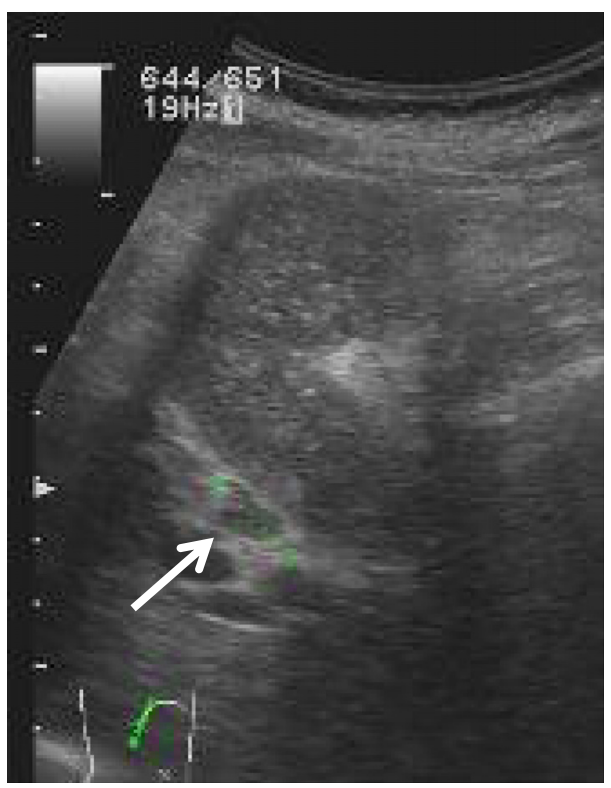

Fig. 1 Ultrasound sonography showed enlarged gallbladder filled with concentrated bile juice and enlarged lymph node along the GB wall. The wall thickness was not detected

MRI showed dilated common bile duct at $18 \mathrm{~mm}$ in diameter and no finding of the anomalous connection with the pancreatic duct (Fig. 3). Although, the dilated intrahepatic bile duct was seen in left liver; this finding was consistently observed in the patient's clinical course and indicated no malignant disease.

According to these findings, we diagnosed the patient with gallbladder carcinoma with lymph node metastasis and performed open cholecystectomy and lymph node dissection of the hepatoduodenal ligament. An analysis of intraoperative frozen sections revealed tumor invasion to the cystic duct; therefore, we additionally resected the extrahepatic bile duct and regional lymph nodes. The concentration of biliary amylase was not elevated at $196 \mathrm{IU} / \mathrm{l}$.

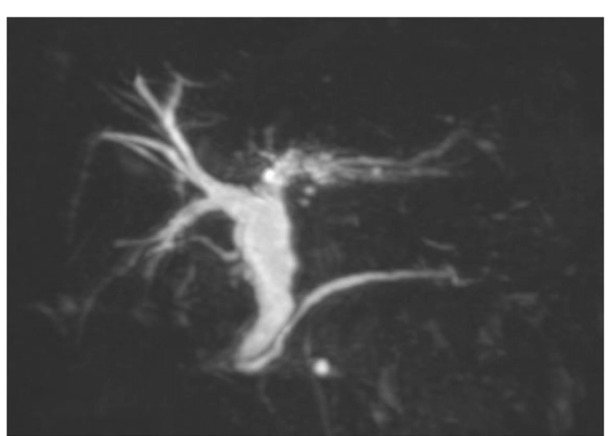

Fig. $3 \mathrm{MRI}$ showed dilated extra hepatic bile duct and intrahepatic bile duct in left liver and no finding of anomalous connection with pancreatic duct

The gross appearance showed a papillary-expanding tumor at the neck of the gallbladder (Fig. 4) and the swelling of the lymph node. A histological examination showed poorly differentiated adenocarcinoma, solid type, and the tumor was limited to the mucosa (Fig. 5). The number of lymphatic vessels was increased in the tumor and peritumor areas, and cancer cells were observed in the lymphatic vessels, which were detected via D2-40 immunohistochemistry (Fig. 6). The clinical and pathological findings were summarized as $\mathrm{GnC}$, papillaryexpanding type, circ, $20 \times 15 \mathrm{~mm}$, por1, med, INF $\beta$, pHinf0, pBinf0, pPV0, ly (1), v0, pn0, s(-), pT1a (M), $\mathrm{pN} 1(2 / 4)$ (12c(1/1), 12p(1/2) 12a(0/1)), DM(0), HM (0), EM (0), according to General Rules for Clinical and Pathological Studies on Cancer of the Biliary Tract. 6th Edition [8].

Although a frozen section of the cystic duct indicated tumor invasion, the tumor invasion into the distal bile duct and perineural invasion were not seen.

The patient was administered gemcitabine $(1000 \mathrm{mg} /$ $\mathrm{m} 2 /$ biweekly) and S1 (100 mg/every other day) as an adjuvant therapy. However, lymph node metastases occurred in the paraaortic and supraclavicular regions, 10 months after the operation. We subsequently added

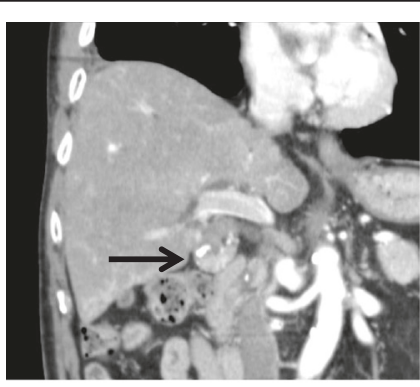

A

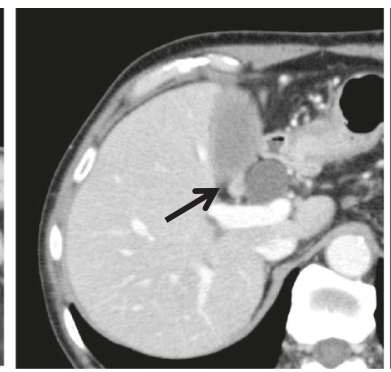

B

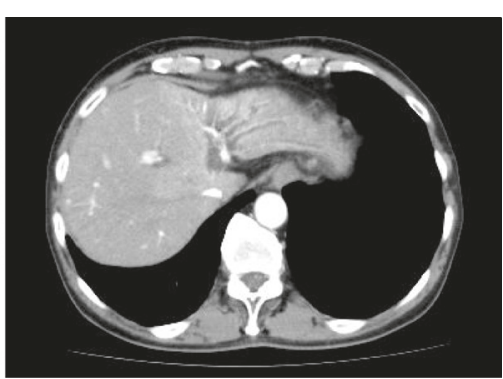

C

Fig. 2 Coronal section of computed tomography indicated contrast-enhanced wall thickness of the neck of the gall bladder (a) and axial section showed swelling of lymph node measuring $1.2 \mathrm{~cm}$ in diameter (b). The dilated intrahepatic bile duct was seen in left liver (c); this finding was consistently observed in the patient's clinical course and indicated no malignant findings 

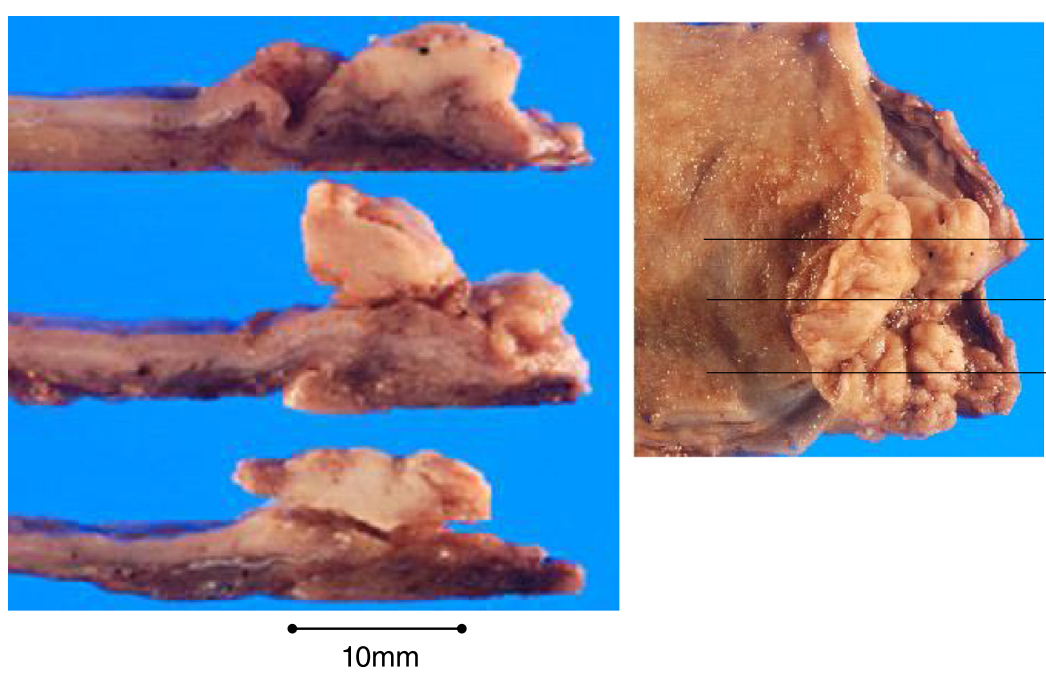

Fig. 4 The gross appearance showed a papillary-expanding tumor at the neck of gallbladder

radiation therapy for both regions and continued gemcitabine and $\mathrm{S} 1$ for 2 years.

\section{Discussion}

Lymph node metastasis is one of the most important prognostic factors of gallbladder carcinoma [9], as well as the depth of tumor invasion, histological grade, and perineural invasion $[5,10,11]$.
The frequency of lymph node metastases by tumor invasion is as follows: T1a, the tumor invaded into the mucosa $0-2.5 \%$; T1b, the tumor invaded into muscularis 5-16\%; T2, the tumor invaded into the perimuscular connective tissue 9-30\%; T3, the tumor perforated into the serosa $39-72 \%$; and $\mathrm{T} 4$, directly invaded into other organs $67-80 \%[7]$.

The wall of the gallbladder is composed of three layers: mucosa, muscularis, and serosa. There is no

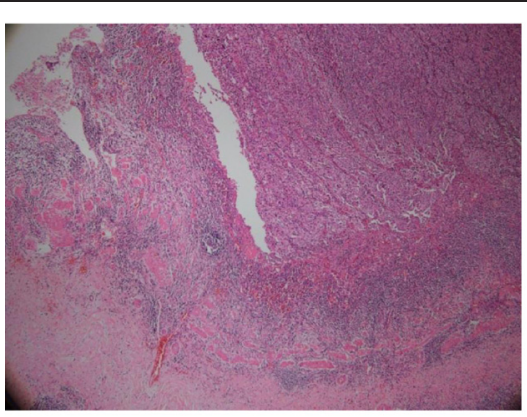

A HE X12.5

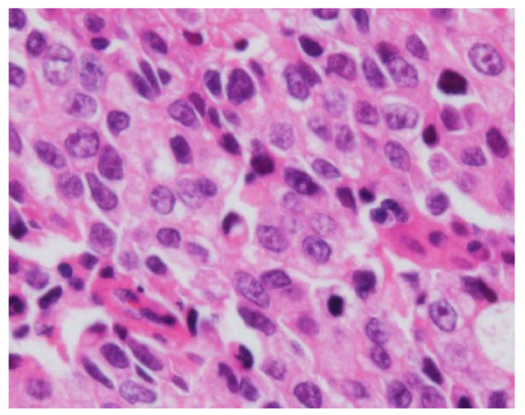

C HE $\times \mathbf{4 0 0}$
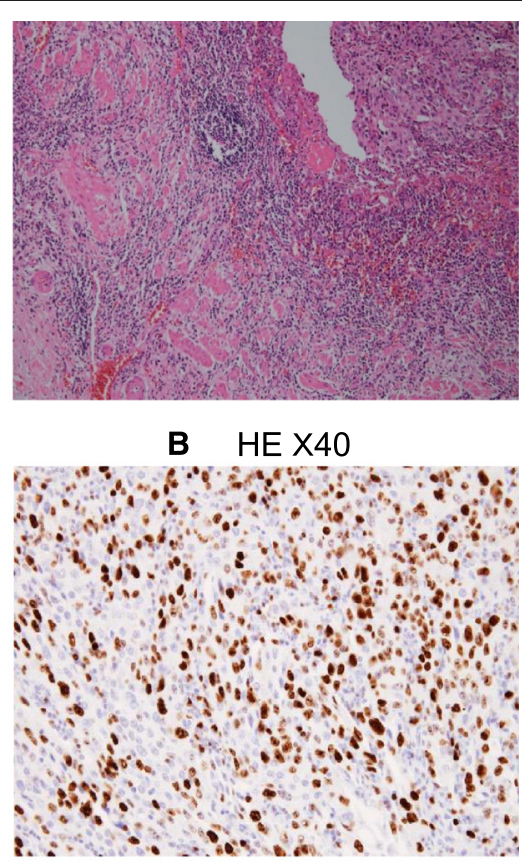

D Ki67 x200

Fig. 5 A histological finding showed cancer was growing limited to the mucosa (a and $\mathbf{b}$ ). According to the no tubular formation and high nuclear grade, it was diagnosed poorly differentiated adenocarcinoma, solid type (c). Ki 67 labeling index was high value at 70-80 \% (d) 


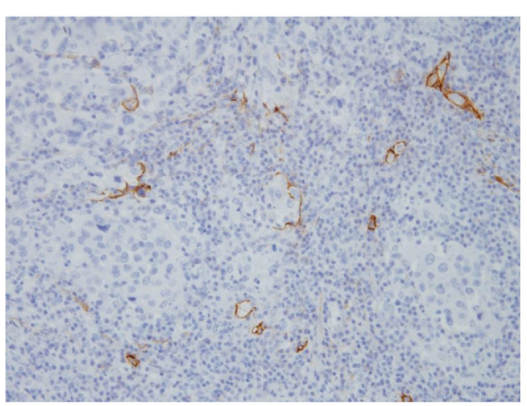

A $\quad \mathrm{D} 2-40 \times 100$

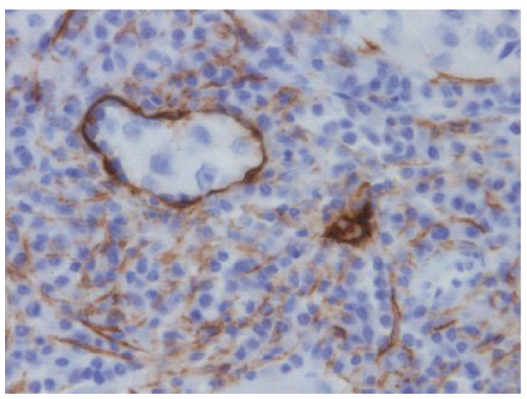

C $\mathrm{D} 2-40 \times 400$

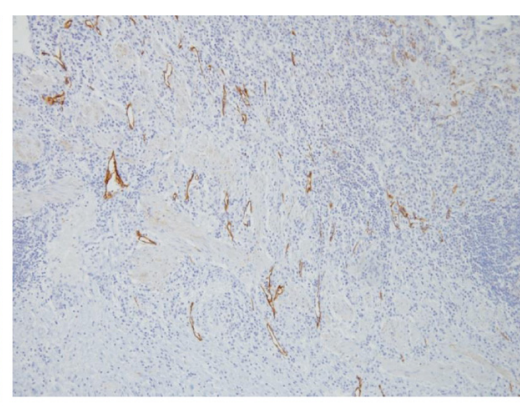

B $\mathrm{D} 2-40 \times 20$

Fig. 6 D2-40 immunohistochemistry; The number of lymphatic vessel was increased in tumor (a) and peritumor areas (b), and cancer cells were observed in the lymphatic vessels $(\mathbf{c})$

muscularis mucosa or submucosa [12]. Tumors in the mucosa easily invade the muscular layer and subserosa. The specific structure of the gallbladder wall might be one of the reasons why T1a GC led to lymph node metastases.

Even in incidental gallbladder carcinoma, T2 (67 \%) and T3 (25\%) diseases are dominant [13]. Only approximately $20 \%$ of patients with incidentally diagnosed GC have early stage disease [13].

The histological grade is strongly related to the prognosis of gallbladder carcinoma. The frequency of lymph node metastases is higher in high nuclear grade tumors or poorly differentiated adenocarcinomas [10].

The specific histological finding in the present case was that lymphatic vessels were observed in the tumor. This finding suggests that cytokines are produced in the tumor tissues which induced the lymphatic vessels. Recent reports have indicated that vascular endothelial growth factor $C$ and $D$ induced neoplastic lymph angiogenesis and were related to lymph node metastasis in several cancers, including gallbladder carcinoma [14-16].

Because a lymph node metastasis was suspected according to the preoperative evaluations in this case, we initially diagnosed the patient with $\mathrm{T} 2$ gallbladder carcinoma and performed lymph node dissection. If a case would be incidentally diagnosed as T1a gallbladder carcinoma, the additional lymph node dissection was not performed according to the guidelines.

\section{Conclusions}

We have experienced a case with T1a gallbladder carcinoma developed lymph node metastases. Therfore, even in T1a gallbladder carcinoma, a careful histological examination and follow-up is required.

\section{Consent}

Written informed consent was obtained from the patient for publication of this case and any accompanying images. A copy of the written consent is available for review by the Editorial-in-Chief of this journal.

\section{Competing interests}

The authors declare no competing interest (COI).

\section{Authors' contributions}

$\mathrm{AT}, \mathrm{HNi}, \mathrm{TO}$, and $\mathrm{MO}$ conceived of this case presentation and drafted the manuscript. SH, MM, HW, HNa, KF, MH, and YM participated in the treatment of this case. All authors read and approved the final manuscript.

\section{Author details}

${ }^{1}$ Department of Surgery, Yamanashi, Japan. ${ }^{2}$ Department of Pathology, Yamanashi, Japan. ${ }^{3}$ Department of Digestive Medicine, Yamanashi, Japan. ${ }^{4}$ University of Tokyo, Tokyo, Japan. ${ }^{5} 1-1-1$ Fujimi Kofu, Yamanashi 400-8506, Japan. 
Received: 31 August 2015 Accepted: 2 November 2015

\section{Published online: 16 November 2015}

\section{References}

1. Miyakawa S, Ishihara S, Horiguchi A, Takada T, Miyazaki M, Nagakawa T. Biliary tract cancer treatment: 5,584 results from the Biliary Tract Cancer Statistics Registry from 1998 to 2004 in Japan. J Hepatobiliary Pancreat Surg. 2009;16:1-7.

2. Ogura Y, Mizumoto R, Isaji S, Kusuda T, Matsuda S, Tabata M. Radical operations for carcinoma of the gallbladder: present status in Japan. World J Surg. 1991;15:337-43.

3. Lee SE, Kim KS, Kim WB, Kim IG, Nah YW, Ryu DH, et al. Practical guidelines for the surgical treatment of gallbladder cancer. J Korean Med Sci. 2014;29:1333-40

4. de Aretxabala XA, Roa IS, Mora JP, Orellana JJ, Riedeman JP, Burgos LA, et al. Laparoscopic cholecystectomy: its effect on the prognosis of patients with gallbladder cancer. World J Surg. 2004;28:544-7.

5. Shirai Y, Yoshida K, Tsukada K, Muto T, Watanabe H. Early carcinoma of the gallbladder. Eur J Surg. 1992;158:545-8.

6. You DD, Lee HG, Paik KY, Heo JS, Choi SH, Choi DW. What is an adequate extent of resection for T1 gallbladder cancers? Ann Surg. 2008;247:835-8

7. Lee SE, Jang JY, Lim CS, Kang MJ, Kim SW. Systematic review on the surgical treatment for T1 gallbladder cancer. World J Gastroenterol. 2011;17:174-80.

8. Japanese Society of Hepato-Biloary-Pancreatic Surgery. General rules for clinical and pathological studies on cancer of the biliary tract. 6th Edition 2013, Kanehara, Tokyo

9. Jensen EH, Abraham A, Jarosek S, Habermann EB, Al-Refaie WB, Vickers SA, et al. Lymph node evaluation is associated with improved survival after surgery for early stage gallbladder cancer. Surgery. 2009;146:706-11. discussion 11-3.

10. Henson DE, Albores-Saavedra J, Corle D. Carcinoma of the gallbladder Histologic types, stage of disease, grade, and survival rates. Cancer. 1992;70:1493-7.

11. Yamaguchi R, Nagino M, Oda K, Kamiya J, Uesaka K, Nimura Y. Perineural invasion has a negative impact on survival of patients with gallbladder carcinoma. Br J Surg. 2002;89:1130-6.

12. Stelow EB, Hong SM, Fierson HF. Gallbladder and extrahepatic biliary system. In Mills SE(ed) Histology for pathologists ed 3, Phyladelphia, 2007, Lippincott Wiliiams \& Wilkins, pp. 705-722.

13. Araida T, Higuchi R, Hamano M, Kodera Y, Takeshita N, Ota T, et al. Should the extrahepatic bile duct be resected or preserved in RO radical surgery for advanced gallbladder carcinoma? Results of a Japanese Society of Biliary Surgery Survey: a multicenter study. Surg Today. 2009:39:770-9.

14. Chen Y, Jiang $L$, She F, Tang N, Wang X, Li X, et al. Vascular endothelial growth factor-C promotes the growth and invasion of gallbladder cancer via an autocrine mechanism. Mol Cell Biochem. 2010;345:77-89.

15. Du $Q$, Jiang $L$, Wang $X$, Wang $M$, She F, Chen $Y$. Tumor necrosis factor-alpha promotes the lymphangiogenesis of gallbladder carcinoma through nuclear factor-kappaB-mediated upregulation of vascular endothelial growth factor-C. Cancer Sci. 2014;105:1261-71.

16. Wang W, Yang ZL, Liu JQ, Jiang S, Miao XY. Identification of CD146 expression, angiogenesis, and lymphangiogenesis as progression, metastasis, and poor-prognosis related markers for gallbladder adenocarcinoma. Tumour Biol. 2012;33:173-82.

\section{Submit your manuscript to a SpringerOpen ${ }^{\circ}$ journal and benefit from:}

- Convenient online submission

- Rigorous peer review

- Immediate publication on acceptance

- Open access: articles freely available online

- High visibility within the field

- Retaining the copyright to your article

Submit your next manuscript at $\gg$ springeropen.com 